\title{
Ambient Ionization and Miniature Mass Spectrometry Systemfor Chemical and Biological analysis
}

\author{
Xiaoxiao Ma and Zheng Ouyang*
}

Weldon School of Biomedical Engineering, Purdue University, West Lafayette, Indiana 47906

*Correspondence should be addressed to

Prof. Zheng Ouyang (ouyang@purdue.edu). 


\section{Abstract}

Ambien ionization and miniaturization of mass spectrometers are two fields in mass spectrometry that have advanced significantly in the last decade. The integration of the techniques developed in these two fields is leading to the development of complete miniature analytical systems that can be used for on-site or point-of-care analysis by non-expert users. Inthis review, we report the current status of development in ambient ionization and miniature mass spectrometers, with an emphasis on those techniques with potential impact on the point-of-care (POC) diagnostics. The challenges in the future development of the integrated systems are discussed with possible solutions presented.

Keywords: Ambient ionization; miniature mass spectrometer; biomarker; therapeutic drug monitoring; quantitative analysis 


\section{Introduction}

Mass spectrometry (MS) has been applied for a wide range of applications in chemical and biological analysis. MS measures the "weight" (through the mass-to-charge ratio $\mathrm{m} / \mathrm{z}$ ) of the analyte molecules, whiletandem MS (MS/MS) can provide valuable informationfor structure elucidation or confirmation. When the two procedures are combined, highly specific identification and highly sensitive quantitation of the analytes can be achieved. The analysis of the real-world complex samples, however, can bevery challenging.For MS, the matrix effects can severely suppress the spectral signal-to-noise ratio $(\mathrm{S} / \mathrm{N})$ of the analytes,disproportionally to their relative concentrations. Furthermore, isomers and/or isobars of the analyte present in the same sample can cause errors in both compound identification and concentration quantitation. The requirement of reducing sample complexity results in the development of various sample extraction methods and modern separation techniques including gas chromatography (GC) and liquid chromatography (LC). Assisted by these developments, MS has now become a versatile technique for both unknown analysis and targetedmonitoring. However, the MS-based analytical systems are constrained for use in lab and by experienced experts.

During the last decade, ambient ionization has emerged and quickly developed for direct analysisusing mass spectrometry, with minimal sample preparation and no chromatographic separation.[1-5] Started with desorption electrospray ionization (DESI)[6] and direct analysis in real time (DART),[7] more than 40 methods have been developed for fast chemical screening and imaging. The future application of the ambient mass spectrometry can be expected to developat threelevelswithdistinctly different purposes and instrumentation platforms,including unknown profiling, targeted monitoring and quantitation, and in situanalysis (Figure 1).

The top two levels of application (Figure 1) represent alternatives to current in-lab MS analysis operation. To performunknown profilinginvolving a relatively large number of analytes in a sample (top level in Figure 1), traditional analytical procedures involving sample preparation and chromatographic separation can be replaced by direct analysis using ambient ionization, which would enable fast survey of the sample for identification of the chemical or biological markers. The use of mass spectrometers of high resolution and high mass accuracy would help the analysis of 
samples of high complexities. Without using traditional sample cleanup or chemical separation, the MS/MS capability would be imperative for distinguishing the isomers or isobars as well as to assure a good sensitivity.[8, 9]For extremely complex samples, the use of ion mobility can further improve the resolving power as well as the sensitivity of the MS analysis. [10]Among the high resolution mass spectrometers with MS/MS capabilities, the Q-Exactive (Thermo Fisher Scientific Inc. San Jose, CA, USA) and the new X series QTOF (AB Sciex LLC, Concord, Ontario, Canada) could be particularly suitable for the unknown profiling using ambient ionization since they are of relatively compact (desktop) size and easy maintenance.

The second level in application would be for quantitation of target analytes in a large quantity of samplesof the same type, which is typically run routinely with regulatory requirements enforced for concentration range, limits of detection (LODs) or quantitation (LOQs). The typical instruments to be used would be triple quadrupole instruments, which is used with LCcurrently for clinical analysis. The use of ambient ionization methods to replace the traditional sample preparation and GC or LC procedures wouldnot only improve the throughput but also minimize the sample consumptionand the chemical waste.[11, 12]The cost for sample storage and shipping can also be significantly reduced.

The methods being developed with ambient ionization for the top two levels of applications would replace some of the procedures currently run in analytical laboratories by experienced operators. An objective for ambient ionization development is to bypass all the current skill requirements for analytical chemists, which leads to simple point-of-care (POC) type operation. The real implementation forin situanalysis, however, would also require an integration of the direct sampling ionization with miniature MS systems. Development of the third level of application with in situ, on-siteanalysis is occurring with miniature MS system, to be usedwith disposable sample cartridges or other sampling kitsfor fast sampling and direct analysis. Ambient ionization would be the key to enable the simple proceduresthat are practically useful for in-field and POC analysis. 


\section{Ambient Mass Spectrometry}

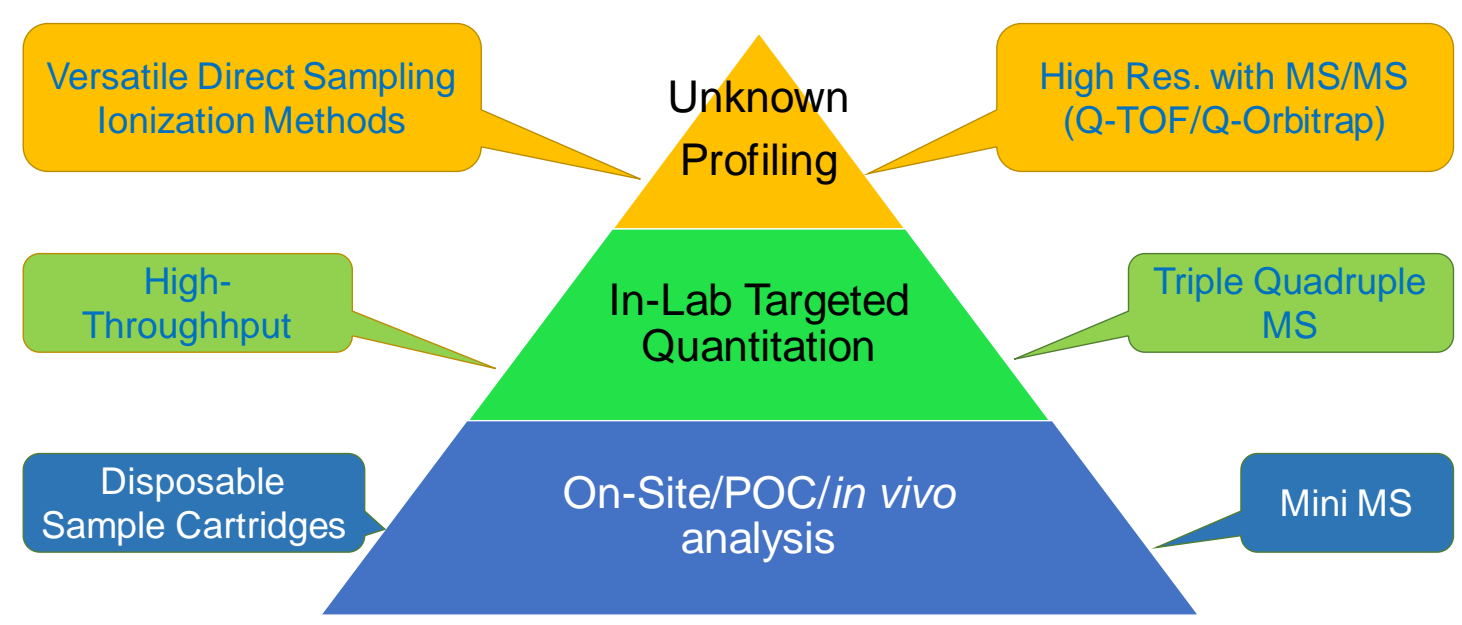

Figure 1. Three levels of chemical analysis by ambient mass spectrometry

The development of miniature MS is analogous to the emergence of desktop computers via miniaturization of large, general-purposecomputers, e.g. ENIAC (Electronic Numerical Integrator and Computer),[13] which has gone through a process withnot only size reduction but alsouser-interface improvement.Ideally, a miniature MS system would be designed for the analysis of various real-world samples via simple operations by users with no training in MS or analytical chemistry.[8, 14] To enable in situMS analysis, two technical challenges need to be overcome. The first challenge is the rapid and highly specific analysis of samples without sample workup or chromatographic separation, which hopefully could be largely resolved with the techniques being developed in the field of ambient ionization. Another challenge is the miniaturization of MS instruments with adequate performance retained for the targeted applications.

In this Review, we discussthe paralleldevelopmentsin both fields of ambient ionization and miniaturization of mass spectrometers, which are critical for the emergence and evolution of on-site and POC analysis. Current status of research will be summarized. The potential of the miniature MS systems with ambient ionization capability will be speculated and the challenges in technical development willbe discussed with potential solutions presented. 


\section{Ambient lonization}

\subsection{Convenient but also sensitive analysis}

The advent of ambient ion sources dates back to theinvention of desorption electrospray ionization (DESI)[6] and direct analysis in real time (DART)[7] one decade ago. The philosophy for the development of ambient ionization was to retain the highly specificity ofMS analysis while greatly reducing the operation complexity. This was achieved by integrating sampling and ionization into a simple and streamlined process. Depending on the intrinsic desorption/ionization mechanisms,[3, 15-18] ambient ionization can be achieved through a one-step "desorption ionization" or a two-step “desorption and then ionization” procedure. Droplet or liquid extraction and laser ablation have been used for sampling; processes similar to those in electrospray ionization (ESI) and atmospheric pressure chemical ionization (APCI) have been used for ionization.Plasmashave been used for generating the reacting species in gas phase for secondary ionization. For instance, in DESI a pneumatically assisted electrospray is directed at the surface of analysis, which firstly forms a thin layer of solvent film[19]and then produces secondary charge droplets through the primary droplet impinging on the liquid film. Ions are subsequently formedthrough the desolvation of the droplets andanalyzed by a mass spectrometer. In DART,[7]dielectric barrier discharge ionization,[20]low temperature plasma probe (LTP) [21]and other plasma-based ambient methods, metastable and charged species have been used to initiate gas phase reactions that lead to ionization of the extracted or desorbed analytes.

Limits of detection (LODs) at low levels of concertation or absolute amounts can be achieved for direct analysis of raw samples using ambient ionization methods. DART-MS was applied for the direct and sensitive detection of trace palladium at a LOD of $1.2 \mu \mathrm{M}$.[21]DART-MS was also applied to newborn screening of phenylketonuria, where a LOD of phenylalanineof $3.0 \mu \mathrm{mol} / \mathrm{L}$ was obtained through analysis of the extraction solution of dried blood spot (DBS).[22] LODs as low as 5 pg were reported for LTP in analysis of explosives of low vapor pressures, such as RDX and TNT on a polytetrafluoroethylene (PTFE) substrate.[21, 23]Sensitive detection of volatile compounds has also been achieved using LTP.[23, 24]Wooden-tip ESI was simple to implement and was demonstrated for quantitative analysis of two drugs of abuse, ketamine and norketamine, in oral 
fluids and urine with LODs of 20 and $50 \mathrm{ng} / \mathrm{mL}$ obtained, respectively.[25] Coated blade spray (CBS) was developed to quantify analytes in the presence of complex matrices.[26] LODs achieved for cocaine and diazepam in plasma and urine were in the $\mathrm{pg} / \mathrm{mL}$ range. Techniques based on liquid extraction(e.g. DESI)are intrinsically advantageous for analysis of biological signatures from animal tissue,[27, 28] plants,[29]micro-organisms[30, 31]and fingerprints.[32] Bypassing the labor-intensive sample extraction and purification, such kind of analyses can be rapidly completed to acquire a qualitative chemical profile of the sample. In one study, DESIwas directly used to detect the anti-tumor drug camptothecin and its derivative (9-methoxycamptothecin) in Nothapodytes nimmoniana(Figure 2a, b).[29]The obtained relative ion intensities suggested that the concentration of camptothecinwas higher in the bark than in the leave and stem.

One exciting research field of ambient ionization is in vivosampling and analysis.One of the most interesting in vivo applications of ambient ionization is the analysis of an awake behaving fly by DART-MS.[33] Pheromones of cuticular hydrocarbons were easily sampled from the surface of a restrained fly, and different hormone compositions of male and female flies were revealed by the fingerprints inMS spectra. Interestingly, the intensities of cis-vaccenyl acetate, tricosene, and pentacosene increasedin virgin females after courtship. This method using ambient ionization allowed near-instantaneous chemical profiling of an individual insect alongside with behavioral studies. Remarkably, the sample to be analyzed can serve as the ion source as well.In another study, spray ionizationwasdirect produced from a plant leave cut into a triangle shape.[34] The glucosinolate cleavage under mechanical stress, as part of the plant self-defense mechanism, was monitored.

A large number of applications using a variety of ambient ionization methods have been developed for tissue analysis. Spray ionization can be directly induced from the biopsy needle with tissue sampled, when applied with 2 5 $\mu \mathrm{L}$ solvent and high voltage (Figure 2c).[35] The tissue biopsy can be rapidly analyzed within a minute, to provide immediate medical evidence. Significant difference was observed in the lipid profiles of normal and cancer (Figure 2d) tissues, which indicated a promising method of low invasiveness for fast disease diagnosis. Probe ESI (PESI)-MS has been applied to in vivo analysis of live mice under surgery(Figure 2e).[36] Mice were anesthetized with the livers exposedfor sampling by aprobe. After sampling, the probe moved upwards and a high voltage was applied on the probe while an auxiliary spray was used to 
castdroplets onto the probe for extracting and ionizing the analytes sampled to the probe. PESI mass spectra of livers of steatotic mice showed increased levels of triacylglycerides (TAG) than controls.[36]Extraction electrospray ionization (EESI) has been used for analysis of human breath. [37]DESI has been used for detection of explosives and drugs of abuse from human skins[38]. With DESI spray directed onto the finger of a person, antihistamine Loratadine became detectable about 40 min after the tablet was taken and remained detectable for another 50 min.[6]The rapid evaporative ionization mass spectrometry (REIMS) allows in vivo, in situ mass spectrometric tissue analysis, based on phospholipid distribution in different tissues.[39] Identification was performed by a combination of principal component analysis (PCA) and linear discriminant analysis (LDA), and the identification accuracy wasbetter than $97 \%$ using a spectral database collected from various tissue species. After initiallyuse for animal tissue analysis, REIMS was later applied to human tissue diagnostics by coupling with electrosurgery, known as the intelligent knife (iKnife).[40] For the data collected during a total of 81 resections, tissue diagnostics by intraoperative REIMS matched the postoperative histological diagnosis at 100\%accuracy.

With the restrictions on the sample size and shape removed with ambient ionization, imaging analysis can be achieved with raw samples of large sizes to obtain highly specific molecular information in a spatially resolved fashion. DESI has been used in tissue imaging with a spatial resolution of at least $200 \mu$ machieved[41]By analyzing lipid profiles, DESI imaging has been used to distinguish diseased human tissues from normal controls.[42, 43] Although many lipid species are common to both types of tissues, their up- or down-regulation can be directly reflected by the relative intensities, resulting in characteristic lipid profiles. Therefore, the lipidomic data collected from DESI imaging could potentially be used for disease diagnostics. [42] 

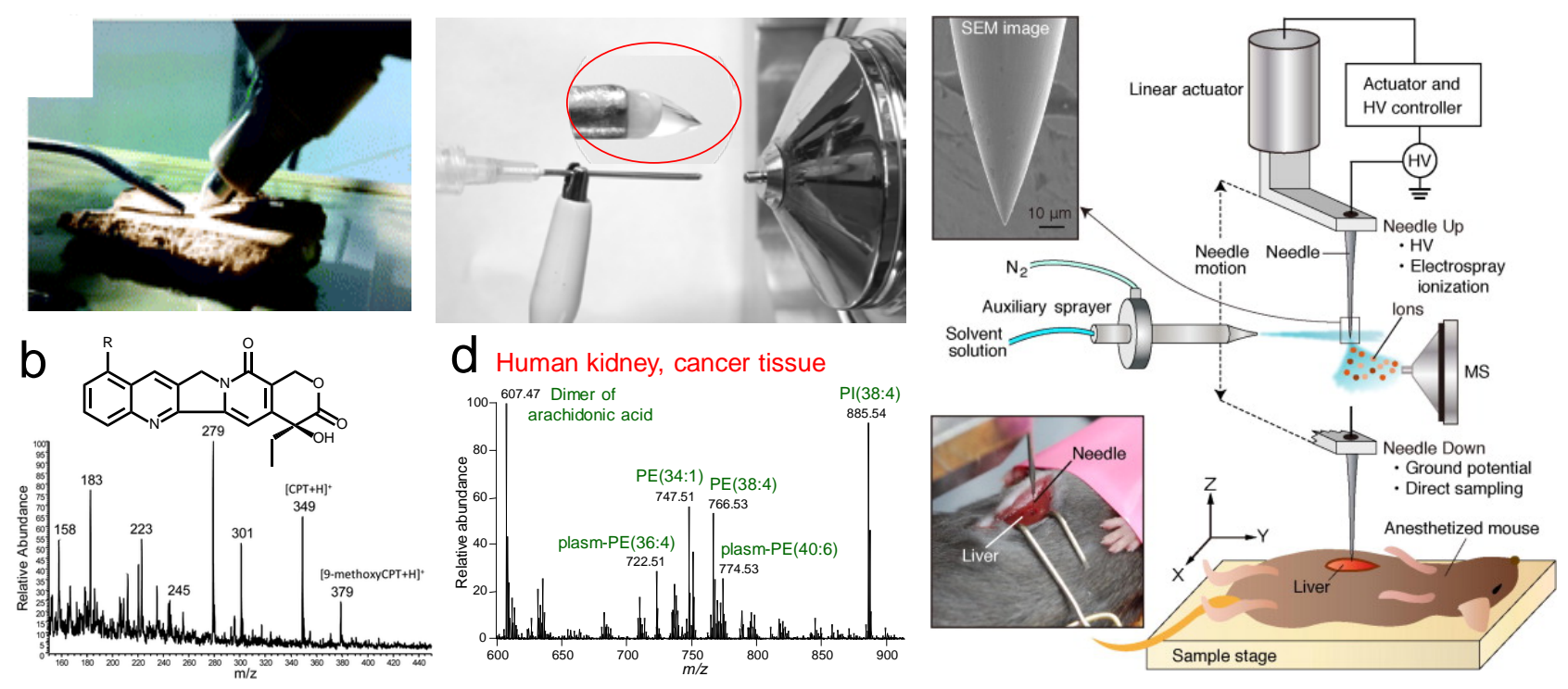

Figure 2. Direct bioanalysis of samples by ambient ionization and MS. (a) Direct analysis of the anti-cancer drug camptothecin and its derivative in Nothapodytes nimmoniana by DESI-MS.(b) DESI-MS spectrum of $N$. nimmoniana bark chip (Reprinted with permission from [29], Royal Society of Chemistry)(c) Biological tissue diagnostics by needle biopsy and tissue spray. (d) Characteristic lipid profile of a cancer tissue of human kidney. (Adapted with permission from [35], American Chemical Society) (e) Schematic of in vivo analysis of mice liver by PESI-MS. (Adapted with permission from [36], Elsevier)

\subsection{Direct Quantitation}

Mandatory precision and sensitivity are often required for targeted monitoring (second or third level in Figure 1). Doctors in clinic settings reply on quantitative results for decision making and disease diagnostics. Personalized medicine and healthcare require the identification of inter-person differences that is dependent on quantitative analysis, in addition to qualitative profiling, of the biomarkers. An intrinsic advantage of MS is the quantitation of a variety of biomarkers at low concentration levels. While semi-quantitation can be simply performed by ambient ionization, the use of internal standards (IS) can significantly improve thelimit of quantitation (LOQ), linear dynamic range, and RSDfor the analysis.Using salicylic acid isotopologue as the IS, DESI-MS was utilized for the quantitation of therapeutic salicylic acid in rat DBS using a three-layer setup for sampling.[44]Good correlation was observed between quantitative results by DESI-MS and LC-MS/MS (Figure 3a, $R^{2}=0.9992$ ). DESI-MS was also applied for the quantitation of the active 
ingredient in anti-malarial drug tablets, based on the noncovalent complexes formed between alkylamine and artesunate on the drug tablet surface.[45] Artesunic acid- $d 4$ was used as the IS deposited on drug tablet surface (in acetonitrile) and let dry under air before DESI-MS analysis. Use of IS greatly increased quantitation precision (RSD 10\%) and make it independent of variations in experimental condition. Paper spray MS was used to develop a large number of quantitative applications. As an example, concentrations of anti-cancer drug imatinibin blood was measured using imatinib- $d 8$ as the IS, with the therapeutic range fully covered by the linear dynamic range (62.5 $\mathrm{ng} \mathrm{mL} \mathrm{m}^{-1} \sim 4 \mu \mathrm{g} \mathrm{mL}^{-1}$ ) (Figure 3b).[46] The liquid extraction-based surface sampling and ionization was demonstrated for the analysis of peptides and small-molecule drugs both qualitatively and quantitatively.[47]Figure 3c shows the calibration curve for sitamaquine in rat blood (10-10, 000 $\mathrm{ng} / \mathrm{ml}$ ) using $570 \mathrm{ng} / \mathrm{ml}$ sitamaquine- $d 10$ as the IS. Extraction spray, combining extraction and electrospray ionization, allowed direct analysis of untreated samples of a volume as low as $0.2 \mu \mathrm{L}$ (Figure 3d).[48]Analytes within dried samples such as DBS on paper substrates were extracted into an organic solvent inside a nanoESI tube and subsequently ionized by nanoESI.By using nanoESI, the spray stability and quantitation performance were improved. LODs for therapeutic drugs, pesticides, fungicides, and contaminants can reach as low as $0.05 \mathrm{pg}$.

In summary, over the past decade, ambient ionization has been greatly advanced in both ion source development and practical applications. Qualitative and quantitative analysis can be achieved through simplified operation procedures for a wide variety of samples. With direct ionization in the open air, samples of various sizes,shapes and conditions (e.g. tissue sections, plants, living animals) can be conveniently analyzed.In comparison with plasma-based method, the ESI-based methods incorporate liquid-liquid or liquid-solid extraction, can ionize nonvolatile analytes, and thereby shall be more suitable for analysis of biological samples. The chemical specificity can be further improved for ambient ionization through on-line reactions, which can enhance the sensitivityof the analysis and will be discussed later in this review. The development of ambient ionization has certainly laid a solid foundation for in situ, on-site analysis that requires minimal sample workup, while miniaturization of mass spectrometers is the other key component for delivering a complete miniatureanalytical system. 


\section{a DESI: salicylic acid in rat blood}

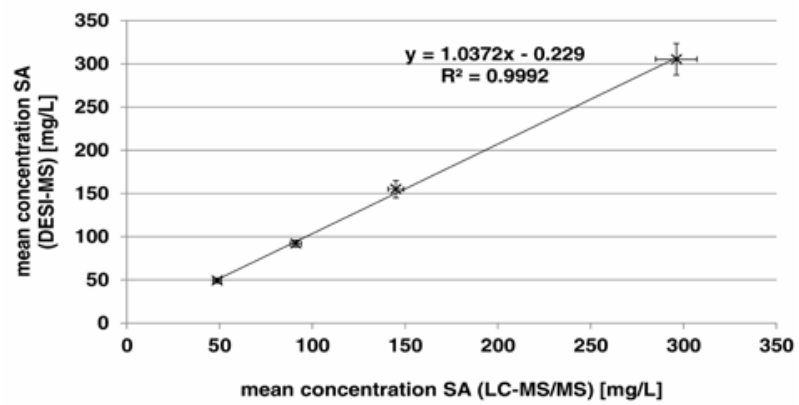

b Paper spray: imatinib in bovine blood

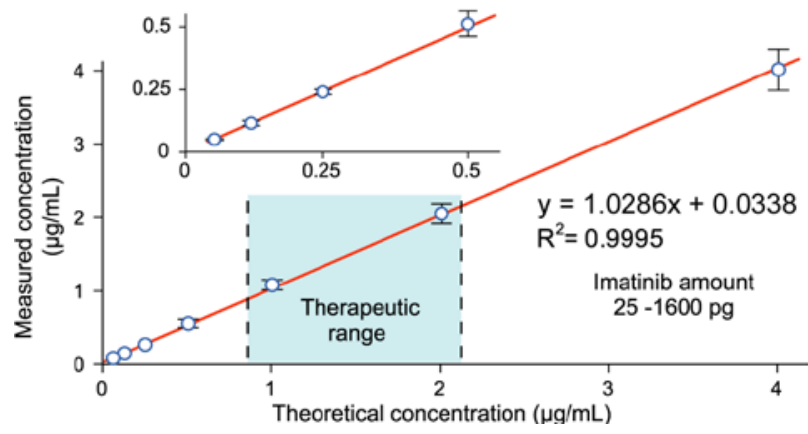

C Liquid extraction: sitamquine in

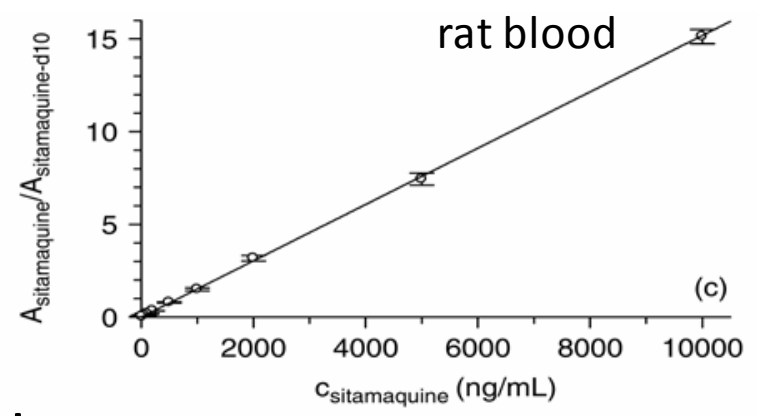

d Extraction spray: amitriptyline in

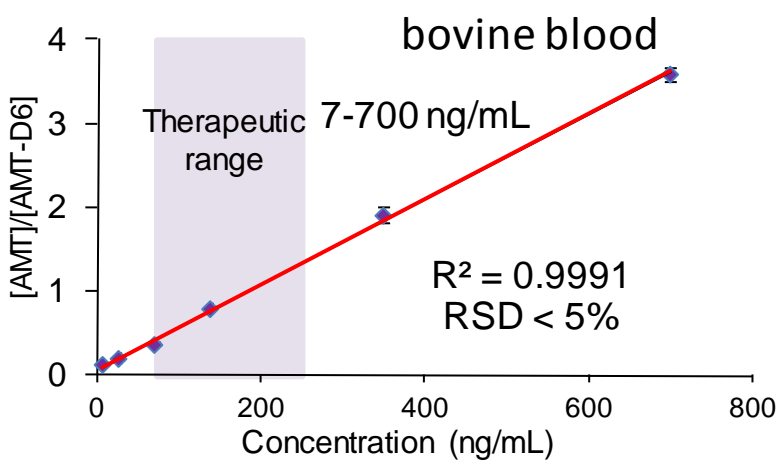

Figure 3. Quantitative analysis by ambient ionization-MS. (a) Good correlation between DESI-MS and LC-MS/MS quantitative results of SA in rat DBS using the three-layer setup (Reprinted with permission from [44], Elsevier) (b) Calibration curve of sitamaquine in rat blood (10-10, $000 \mathrm{ng} / \mathrm{ml}$ ) using $570 \mathrm{ng} / \mathrm{ml}$ sitamaquine- $d 10$ as the IS. (Reprinted with permission from[47], Wiley)(c) Calibration curve for the analysis of sitamaquine in rat blood by liquid extraction-based surface sampling and ionization using sitamaquine- $d 10$ as the IS.(Reprinted with permission from[47], Wiley) (d) Calibration curve for analysis of amitriptyline in blood samples using extraction spray, MRM transition $\mathrm{m} / \mathrm{z} 277$ to 223 for amitriptyline and $\mathrm{m} / \mathrm{z} 283$ to 223 for internal standard amitriptyline- $d 6$ ( $200 \mathrm{ng} / \mathrm{mL}$ ), $0.2 \mu \mathrm{L}$ blood used for DBS, $10 \mu \mathrm{L}$ methanol for extraction and spray. (Adapted with permission from [48], The Royal Society of Chemistry)

\section{Miniature Mass Spectrometry Systems}

Miniaturization of mass spectrometers has been advancing rapidly in the last two decade[14] and is about to make a major impact on the MS instrument products and applications. Highly portable 
mass spectrometers have been developed using small pumping systems,[23, 49-51] compact electronics and miniaturized mass analyzers.[49, 50]This type of instruments includes the shoebox size Mini 10 of 10 kg,[49] Mini 11 of 4 kg,[50] a desktop size Mini 12 of 25 kg,[51] and a backpack miniature MS instrument.[23, 52]Analysis by miniature MS is expected to play a unique role in bioanalysis in that it allows users such as biologists, nurses, physicians to get the MS analysis results at their own benches or desks, without a need to send the samples to the analytical laboratories. To achieve this ultimate goal, the miniature mass spectrometers should not only be small in size, light in weight, with adequate analytical performance, but also with extremely simplified operational procedures. Analysis using miniature MS is highly likely for target analytes in target samples, so simple analysis procedures as well as fast data processing can be performed for a narrow range of analytes in specialized applications. However, the scope of the applications byminiature MS by no meansislimited to a small number of application types, as long as the simple operation and direct result reporting can be developed for each of the target applications. The combination of ambient ionization with miniature mass spectrometer certainly plays a key role in the development strategy, which however requires an atmospheric pressure interface on the miniature mass spectrometers. This can be extremely challenging with the pumping systems of small sizes, light weights, simple configurations, and consequently low pumping capacities. The discontinuous atmospheric pressure interface was developed to solve the problem, which uses a pinch valve to introduce ions from open air intermittently (Figure 4a).[53, 54]

Capability of direct analysis of biological samples, such as blood, urine or tissue, would be important for using miniature MS systems in POC applications. Disposable cartridge has been developed for use of paper spray in analysis of biofluid samples (Figure 4b). [51]A paper substrate with a sharp tip was sandwiched into a plastic cassette. The biofluid sample was deposited onto the paper to form a dried spot. For the analysis, a solvent of about $10-30 \mu \mathrm{L}$ was deposited into the cartridge, which wetted the paper, extracted the analyte for a spray ionizationwith a DC voltage $(\sim 3$ $\mathrm{kV}$ ) applied. This cartridge has also been used for direct analysis of solid samples such as the orange peels containing agrochemical residues.The Mini 12 system was a desktop instrument designed for demonstration of the potential POC MS analysis, with a series of ambient ionization methods tested.[51] Using the extraction spray ionization, therapeutic drugs in blood samples have been analyzed (Figure 4c) with LOQs below $10 \mathrm{ng} / \mathrm{mL}$ and RSD better than $10 \%$ achieved. 
Flexible sampling ionization probes as long as $4 \mathrm{~m}$ have been developed for in vivo tissue examinations, which can potentially be used for endoscopic examination.[55]A dual-channel configuration was used in the probe designs, with one channel delivering the charged droplets for desorption ionization (as in DESI) and the other one for transferring the ions back to the mass

spectrometer. An integrated miniature system with such a probe has also been developed.[56] A flexible and light-weight sampling probe was integrated into a modified Mini 10 (Figure 4). The system was tested by analyzing tissue samples such as those from rat brain and lung, and different lipid profiles were obtained (Figure 4f, 4g).

Although a significant effort has been put into the miniaturization of the mass spectrometers, as products the small instruments are still at their infancy stage. Novel but non-conventional approaches, such as the discontinuous atmospheric pressure interface or the sampling probe, enabled the significant reduction of instrument size but would need further improvement to make the integrated instrument package robust for daily use. The MS/MS capability, important for ambient ionization, could also compensate for the compromise in mass accuracy or mass resolution. 

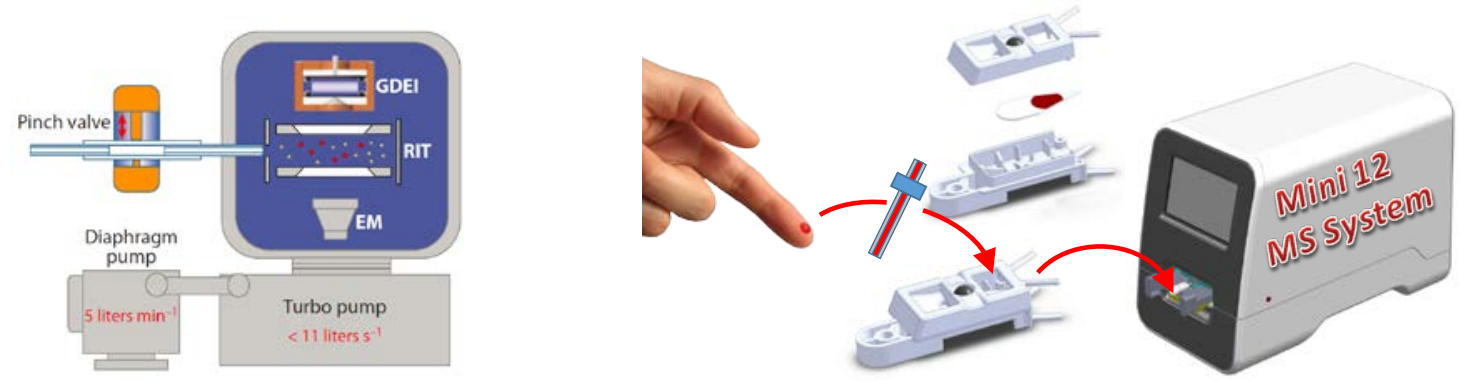

C

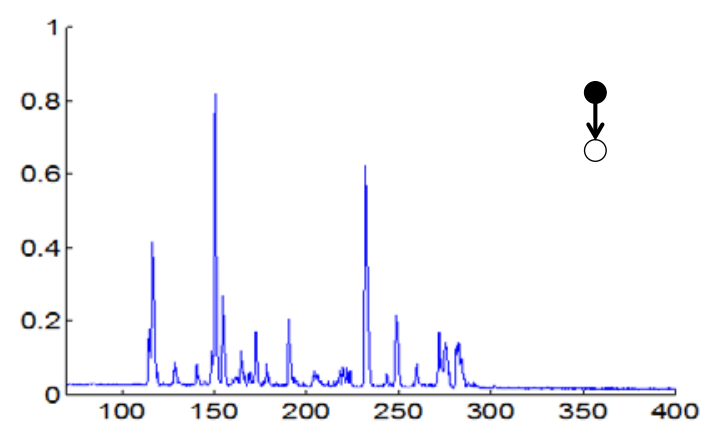

\begin{tabular}{|c|c|c|c|c|c|c|}
\hline $\begin{array}{c}\text { Concentration } \\
(\mathrm{ng} / \mathrm{mL})\end{array}$ & 7.5 & 15 & 60 & 120 & 210 & 510 \\
\hline RSD (n=3) & 10.13 & 9.53 & 6.47 & 8.63 & 4.78 & 7.11 \\
\hline 3
\end{tabular}
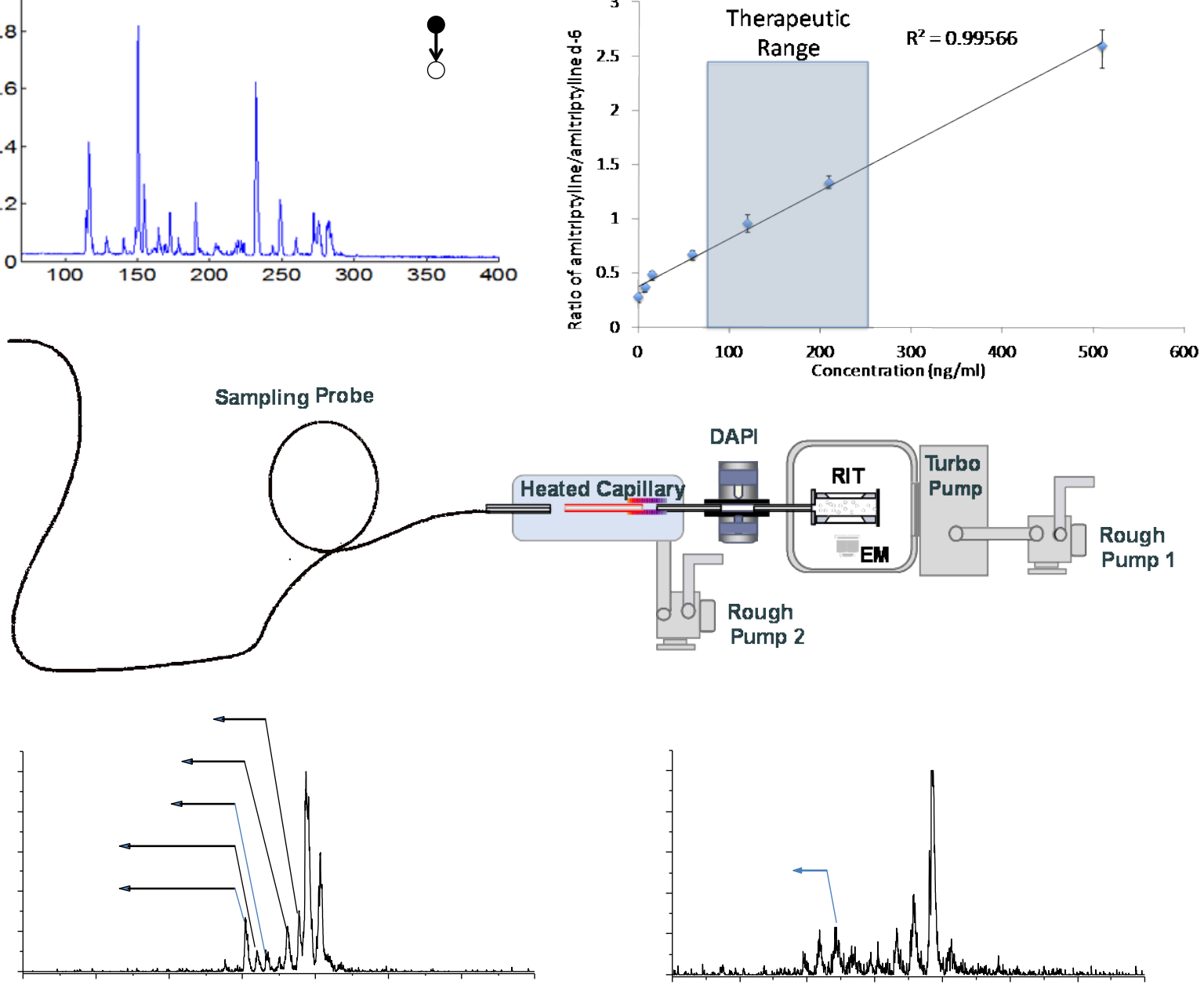

Figure 4.DAPI interfaced with Mini 12 and Mini 10 equipped with a sampling probe for bioanalytical applications.(a) DAPI interfaced to a miniature RIT mass analyzer. (Reprinted with permission from [14])(b) Mini 12 PS-MS system. (c)Analysis of 50 ng of amitriptyline in blood by PS-MS/MS on Mini 12. (d) Calibration curve for quantitation of amitriptyline in blood by extraction spray ionization using amitriptyline- $d 6$ as the IS.(Adapted with permission from [51], American 
Chemical Society) (e) Schematic of the miniature MS system with an integrated sampling probe. (f, g) Direct analysis of tissue sections of rat brain (f) and lung (g) by the miniature MS system equipped with a1.5 m long sampling probe. (Reprinted with permission from [56], American Chemical Society)

\section{Future Challenges and Solutions}

The integration of the ambient ionization and miniature mass spectrometer for direct sampling analysis represents a major direction in future MS instrumentation for in-situ and POC applications. It is worth noting that ambient ionizationmethods, most of which have been developed using commercial instruments, may not be directly transferrable to miniature MS systems and an adaptationmight be requiredat different levels. As one of the most studied ambient ionization methods, DESI has been applied in various applications, such as high-throughput analysis,[11, 12, 57] reaction monitoring and mechanistic studies,[58-60] and bio-imaging;[27, 28, 32]however, the high flow rate of the nebulizing gas represents a significant difficulty for practical implementation with a miniature MS system to be operated in a physician’s office. However, with the design of the probe utilizing the nebulizing gas as the carrier gas for transferring the ions back from tissue sample, the miniature MS system forpotential endoscopic examination was developed.[56] The low-temperature plasma (LTP) probe[21]uses no solvent and low flow rate $(0.4 \mathrm{~L} / \mathrm{min})$ for the discharge gas, and therefore could be suitable for portable MS systems.The alternative configurations recently developed [52][61]really made the LTP much more feasible for use with in-field analytical systems such as the backpack MS instrument.Paper spray has being widely applied in the direct analysis of biological samples including tissues,[62] serum,[63]and whole blood, [64] as well as high-throughput analysis.[65]With the design of disposable cartridges, POC therapeutic drug monitoring can now be readily implemented with miniature MS systems.[51]

Compatibility of disposable sample cartridges or sampling kits should be one of the major considerations for selecting ambient ionization methods for in-situ and on-site applications using miniature MS systems. Paper spray has been demonstrated as a good method for analysis of dried 
sample spots made from biofluid samples of small amounts (lower than $10 \mu \mathrm{L}$ ), which can be taken using minimally invasive methods. A recent improvement of paper spray useda capillary emitter in conjunction with a paper substrate, which is easier for mass production of the cartridge and makes the paper spray concept compatible with more types of mass spectrometers using different atmospheric pressure interfaces (Figure 5a,b).[66]Similar with extraction spray, the use of a glass tip made the spray current much more stable than the originally cut paper tip. This was shown to be critical for miniature MS instruments to obtain good precision in quantitation.

For direct analysis of biofluid samples in liquid forms without making them into dried sample spots, slug flow microextraction (SFME) nanoESI (Figure 5c) represents an easy means of real time extraction and ionization for MS analysis using lab-scale (Figure 5d) [67] or miniature mass spectrometers.[68] A liquid-liquid extraction was performed in a nanoESI tube between the biofluid sample and an organic solvent. An efficient extraction and mixing of IS or reagents for on-line derivatization were facilitated by the slug motions of the liquid plugs. Enzymatic reactions in blood could also be monitored using the SFME nanoESI.The microextraction prior to nanoESI could certainly help to minimize the contamination of the MS instruments. As expected, the extraction process would work more efficiently for the analytes of lower polarity; however, relatively polar compounds, such as benzoylecgonine, could also be detected at good LOD $(0.1 \mathrm{ng} / \mathrm{mL}),[67]$ since relatively higher ionization efficiency could be obtained with subsequent nanoESI process.

Based on our past experience with LTP, paper spray, extraction spray or slug flow microextraction nanoESI, the transfer of an ambient ionization method from lab-scale MS systems to miniature MS systems can result in a 10-time loss in sensitivity. A variety of different methods can be sued for improvements. For instance, use of silica-coated paper allowed a sensitivity increase of one order of magnitude for paper spray, which has been demonstrated with both commercial triple quadrupole and home-built miniature mass spectrometers.[69] Application of a cleaning procedure for the paper substrate has also helped to reach a better LOQ for quantitation of drugs of abuse.[70] On-line chemical derivatization is another effective way of increasing the specificity as well as the sensitivity for direct analysis. This has been demonstrated with the Schiff base reactions for analysis of anabolic steroids in urine samples using DESI [71] or slug flow microextraction nanoESI (Figure 5e, f),[67] charge labeling reaction by betaine aldehyde for analysis of cholesterol in serum using DESI [72] or paper spray.[73]Reactions with cysteamine was also used for direct analysis of 
quinones in urine, serum and cell culture medium.[74] The recent studies on the acceleration of the reaction in charged droplets[75-77] have a huge implication to the future developmentof ambient ionization methods with on-line derivatizations incorporated.
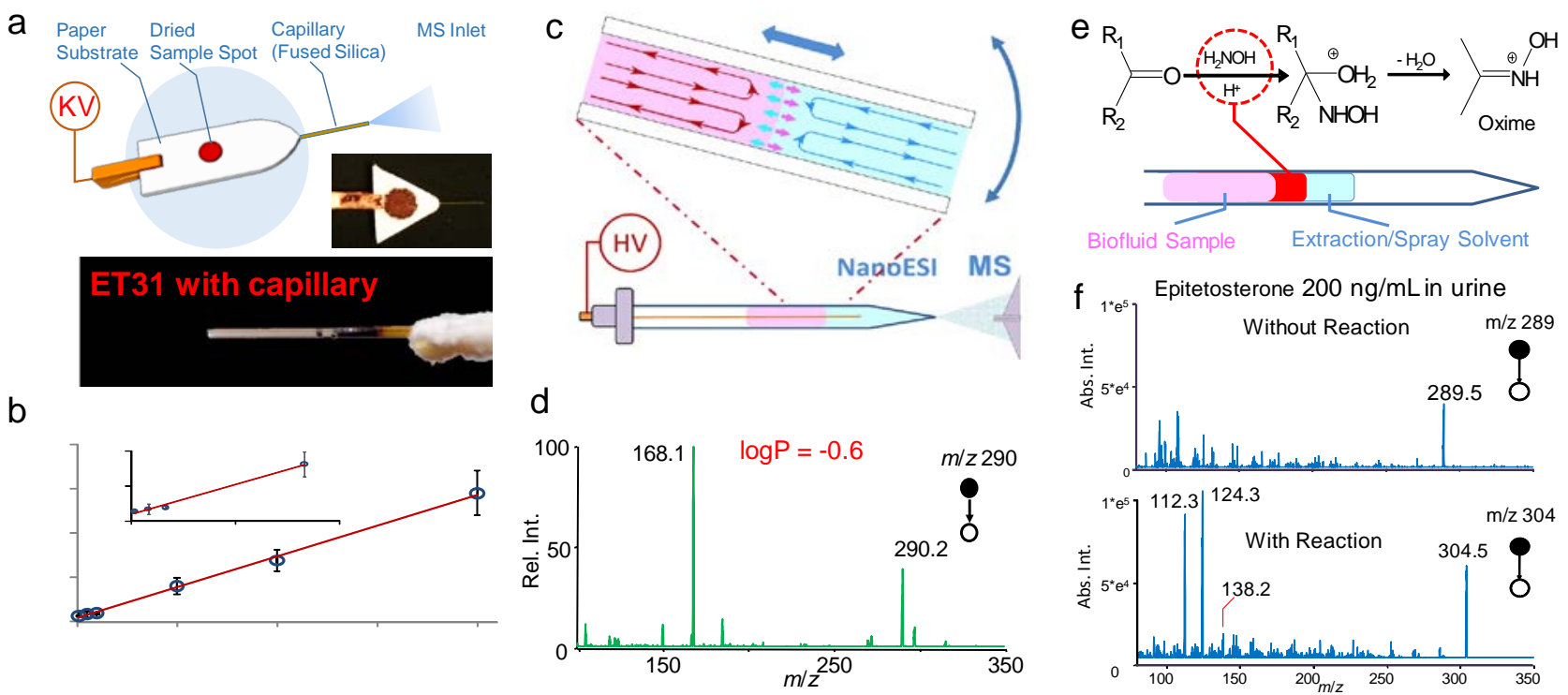

Figure 5. Techniques developed to simplify, improve, and speed up qualitative and quantitative

bioanalysis by miniature-MS. (a) Paper-capillary spray capable of direct MS analysis of biofluids. (b) Calibration curve of sitagliptin in bovine whole blood, established using Mini12 and paper-capillary spray (Adapated with permission from [66], Springer). (c) Sample extraction by slug-flow microextraction (SFME) in a nESI tube, followed by nanoESI-MS analysis. (d) MS/MS analysis of $50 \mathrm{ng} \mathrm{mL}^{-1}$ benzoylecgonine in $5 \mu \mathrm{L}$ urine. (Adapted with permission from [67],Wiley). (e) Reactive SFME-nanoESI with a reagent plug injected between the biofluid sample and the extraction solvent. (f) MS/MS spectra from direct and reactive SFME-nanoESI analysis of $200 \mathrm{ng}$ $\mathrm{mL}^{-1}$ epitestosterone in synthetic urine $(5 \mathrm{~mL}$ water containing $50 \mathrm{~mm}$ hydroxylamine was used as the liquid reagent plug, Adapted with permission from [67], Wiley).

Development of miniature MS systems with direct sampling ionization capabilities no doubt will have a significant impact on the medical diagnostics and other regulatory applications, which have mandatory criteria for quantitative performance of the analytical systems and methods. The traditional quantitation method used for MS analysis involves internal standards and MRM 
(multi-reaction monitoring) analysis. In direct analysis of raw samples using ambient ionization, use of external calibration is simple and might work well for some of the applications, but incorporation of internal standards is expected to be and has been demonstrated to be more reliable for providing accurate quantitative results.[8]Accurately adding IS into samples of small amounts while keeping the entire procedure simple can be extremely challenging, since traditional lab techniques may not be used.This can be and needs to be one of the most innovative fields in future development of ambient ionization for on-site analysis. Some methods have been explored, with promising results obtained. Preprinting IS compounds on paper substrates has been tried for quantitation using paper spray MS, with good quantitative performance (RSD = 8\%) achieved.[78] However, dedicated sample deposition was required, which can be challenging for routine use by non-expert users. In another work, capillaries pre-coated with IS was used to achieve accurate aspiration and deposition of liquid samples while mixing the IS into the samples automatically (Figure 6a, 6b).[79] The collected sample was then deposited on a paper substrate for subsequent analysis. Since the amounts of both IS and the sample were determined by the capillary volume, excellent quantitative performance (RSD $<5 \%$ ) was obtained, at a sample volume as low as $1 \mu \mathrm{L}$.
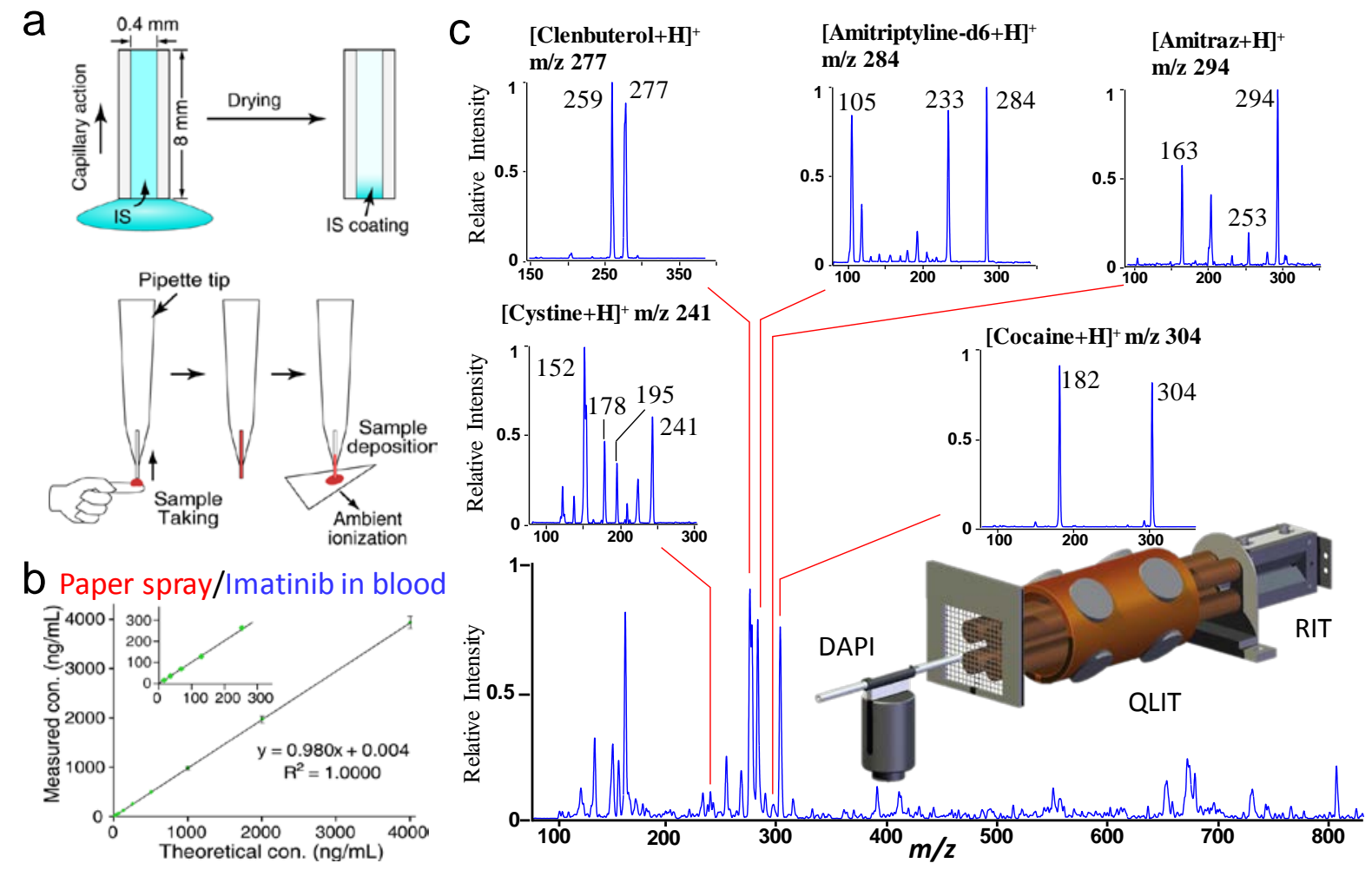


\section{Figure 6. Internal standard introduction technique anddual trap design to enhance the}

performance of the miniature MS system. (a) Development of a simple, accurate and reproducible IS introduction and sample deposition using a capillary sampler $(0.4 \mathrm{~mm}$ i.d., about $8 \mathrm{~mm}$ long). The capillary is filled with IS solution via capillary action. After drying in the air an IS coating is formed on the inner surface. The IS-loaded capillary was then used for blood sampling and deposition, during which the analyte is pre-mixed with the IS before MS analysis. (b) Analysis of imatinib in blood (10-4000 ng/mL) by PS-MS, where the capillary sampler was coated with imatinib- $d 8$ as IS (Reprinted with permission from [79], American Chemical Society). (c)Dual linear ion trapMS equipped with DAPI (DAPI-QLIT-RIT) for MS analysis. Analysis of a analyte mixture containing 1

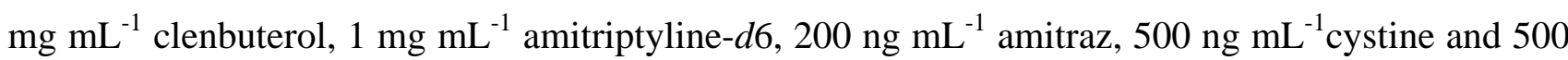
ng $\mathrm{mL}^{-1}$ cocaine. Insets for MS/MS spectra of cystine, cocaine, clenbuterol, amitriptyline- $d 6$, and amitraz in the mixture. (Reprinted with permission from[80], Royal Chemical Society)

As consistently stated in the review, the future applications for the miniature MS systems are expected to be mainly for target analysis. However, the actual chemical and biological markers each can be a single compound or a suite of compounds. One example is the direct, quantitative profiling of a panel of 10 acylcarnitines that can serve as biomarkers for the fatty acid oxidation disorders. Paper spray was used with a triple quadrupole instrument running multiple MS/MS scans for the profiling.[63] When transferring this type of applications to miniature MS systems, relatively high speed MS/MS scan is highly desirable. Currently it takes about 1s for the Mini 12 system to run a single MS/MS scan, which is quite acceptable for analyzing a single compound in any POC application. The relatively long scan time, in comparison with 0.1 s for commercial lab-scale instrument, is due to the elevation of the pressure in vacuum chamber after each ion introduction and a delay time of about $500 \mathrm{~ms}$ for the vacuum recovery. The ions were trapped at high pressure ( 100 mTorr) and subsequently analyzed at low pressure ( $\sim$ mTorr). A new design with dual linear ion traps has been developed for future miniature MS systems operating with ambition ionization sources (Figure 5c). The first ion trap was used to store ions of all the biomarkers introduced all at once, and then the ions of each species were sequentially sent to the second ion trap for MS/MS analysis. Duty cycle close to lab-scale mass spectrometers has been achieved. The additional advantage of this design is the improved quantitation precision, since the ions of 
theanalyte and its internal standard to be mass analyzed could always be introduced into the mass spectrometer at the same time.

\section{Conclusions and Perspectives}

Miniature MS systems with ambient ionization capability can be a powerful tool for POC analysis and their applications in biomedical arena is promising and exciting. The ease of implementing and using these systems for on-site analysis by non-expert users will bring a paradigm shift in the future MS applications. Although ambient ionization methods have been explored for direct analysis of large molecules such as proteins [81, 82], the applications immediately suitable for the POC MS systems might involve only organic metabolites and lipids. Effective real-time extraction from biological samples and subsequent ionization at relatively high efficiency have been well demonstrated with a variety of ambient ionization methods.[47, 67]The circulating proteolytic products in biofluids [83] might also become suitable biomarkers for screening by the small MS systems.The spray-based methods, in comparison with plasma-based ones, might be of an advantage for the ease of extraction and ionization of biomolecules.

The performance of the future miniature mass spectrometers designed for the on-site analysis may not be judged by the criteria set for in-lab large instruments. It would be necessary to increase the $\mathrm{m} / \mathrm{z}$ range of the current Mini 10 for analysis of lipids or peptides. Implementation of the characteristic MS/MS transitions identified for the target analytes into the analysis would significantly increase the specificity, which otherwise however might be compromised due to the relatively low mass resolution and accuracy of the miniature MS systems. "Adequate performance”, instead of "ultimate high performance”, should be the key strategy for system design for achievinga balance among the size reduction, ease of use and required specification. 


\section{Acknowledgement}

The reported research performed at Purduewas supported by National Science Foundation (Project CHE-0847205) and National Institutes of General Medical Sciences (Projects 1R21 RR031246 and 1R01GM106016) of National Institutes of Health. 


\section{Reference}

[1] R.G. Cooks, Z. Ouyang, Z. Takats, J.M. Wiseman, Ambient Mass Spectrometry, Science, 311 (2006) 1566-1570.

[2] Z. Ouyang, X. Zhang, Ambient mass spectrometry, Analyst, 135 (2010) 659-660.

[3] M.E. Monge, G.A. Harris, P. Dwivedi, F.M. Fernández, Mass Spectrometry: Recent Advances in Direct Open Air Surface Sampling/lonization, Chemical Reviews, 113 (2013) 2269-2308.

[4] P. Nemes, A. Vertes, Ambient mass spectrometry for in vivo local analysis and in situ molecular tissue imaging, TrAC Trends in Analytical Chemistry, 34 (2012) 22-34.

[5] M.-Z. Huang, C.-H. Yuan, S.-C. Cheng, Y.-T. Cho, J. Shiea, Ambient Ionization Mass Spectrometry, Annual Review of Analytical Chemistry, 3 (2010) 43-65.

[6] Z. Takáts, J.M. Wiseman, B. Gologan, R.G. Cooks, Mass Spectrometry Sampling Under Ambient Conditions with Desorption Electrospray Ionization, Science, 306 (2004) 471-473.

[7] R.B. Cody, J.A. Laramée, H.D. Durst, Versatile New Ion Source for the Analysis of Materials in Open Air under Ambient Conditions, Analytical Chemistry, 77 (2005) 2297-2302.

[8] X. Zhou, J. Liu, R.G. Cooks, Z. Ouyang, Development of miniature mass spectrometry systems for bioanalysis outside the conventional laboratories, Bioanalysis, 6 (2014) 1497-1508.

[9] C.R. Ferreira, K.E. Yannell, A.K. Jarmusch, V. Pirro, Z. Ouyang, R.G. Cooks, Ambient Ionization Mass Spectrometry for Point-of-Care Diagnostics and Other Clinical Measurements, Clin Chem, 62 (2016) 99-110.

[10] F. Lanucara, S.W. Holman, C.J. Gray, C.E. Eyers, The power of ion mobility-mass spectrometry for structural characterization and the study of conformational dynamics, Nat Chem, 6 (2014) 281-294.

[11] N.E. Manicke, T. Kistler, D.R. Ifa, R.G. Cooks, Z. Ouyang, High-Throughput Quantitative Analysis by Desorption Electrospray Ionization Mass Spectrometry, Journal of the American Society for Mass Spectrometry, 20 (2009) 321-325.

[12] H. Chen, N.N. Talaty, Z. Takáts, R.G. Cooks, Desorption Electrospray Ionization Mass Spectrometry for High-Throughput Analysis of Pharmaceutical Samples in the Ambient Environment, Analytical Chemistry, 77 (2005) 6915-6927.

[13] S. McCartney, ENIAC: The triumphs and tragedies of the world's first computer, Walker \& Company, New York, 1999.

[14] Z. Ouyang, R.G. Cooks, Miniature Mass Spectrometers, Annual Review of Analytical Chemistry, 2 (2009) 187-214.

[15] G.A. Harris, L. Nyadong, F.M. Fernandez, Recent developments in ambient ionization techniques for analytical mass spectrometry, Analyst, 133 (2008) 1297-1301.

[16] G.A. Harris, A.S. Galhena, F.M. Fernández, Ambient Sampling/lonization Mass Spectrometry: Applications and Current Trends, Analytical Chemistry, 83 (2011) 4508-4538.

[17] A. Venter, M. Nefliu, R. Graham Cooks, Ambient desorption ionization mass spectrometry, TrAC Trends in Analytical Chemistry, 27 (2008) 284-290.

[18] G.J. Van Berkel, S.P. Pasilis, O. Ovchinnikova, Established and emerging atmospheric pressure surface sampling/ionization techniques for mass spectrometry, Journal of Mass Spectrometry, 43 (2008) 1161-1180.

[19] A.B. Costa, R.G. Cooks, Simulation of atmospheric transport and droplet-thin film collisions in desorption electrospray ionization, Chemical Communications, DOI 10.1039/B710511H(2007) 
3915-3917.

[20] N. Na, M. Zhao, S. Zhang, C. Yang, X. Zhang, Development of a Dielectric Barrier Discharge Ion Source for Ambient Mass Spectrometry, Journal of the American Society for Mass Spectrometry, 18 (2007) 1859-1862.

[21] J.D. Harper, N.A. Charipar, C.C. Mulligan, X. Zhang, R.G. Cooks, Z. Ouyang, Low-Temperature Plasma Probe for Ambient Desorption Ionization, Anal Chem, 80 (2008) 9097-9104.

[22] C. Wang, H. Zhu, Z. Cai, F. Song, Z. Liu, S. Liu, Newborn screening of phenylketonuria using direct analysis in real time (DART) mass spectrometry, Analytical and Bioanalytical Chemistry, 405 (2013) 3159-3164.

[23] P.I. Hendricks, J.K. Dalgleish, J.T. Shelley, M.A. Kirleis, M.T. McNicholas, L. Li, T.-C. Chen, C.-H. Chen, J.S. Duncan, F. Boudreau, Autonomous in situ analysis and real-time chemical detection using a backpack miniature mass spectrometer: concept, instrumentation development, and performance, Analytical chemistry, 86 (2014) 2900-2908.

[24] X. Ma, S. Zhang, Z. Lin, Y. Liu, Z. Xing, C. Yang, X. Zhang, Real-time monitoring of chemical reactions by mass spectrometry utilizing a low-temperature plasma probe, Analyst, 134 (2009) 1863-1867.

[25] P.-K. So, T.-T. Ng, H. Wang, B. Hu, Z.-P. Yao, Rapid detection and quantitation of ketamine and norketamine in urine and oral fluid by wooden-tip electrospray ionization mass spectrometry, Analyst, 138 (2013) 2239-2243.

[26] G.A. Gómez-Ríos, J. Pawliszyn, Development of Coated Blade Spray Ionization Mass Spectrometry for the Quantitation of Target Analytes Present in Complex Matrices, Angewandte Chemie, 126 (2014) 14731-14735.

[27] J.M. Wiseman, D.R. Ifa, Q. Song, R.G. Cooks, Tissue Imaging at Atmospheric Pressure Using Desorption Electrospray Ionization (DESI) Mass Spectrometry, Angew. Chem. Int. Ed., 45 (2006) 7188-7192.

[28] J.M. Wiseman, D.R. Ifa, Y. Zhu, C.B. Kissinger, N.E. Manicke, P.T. Kissinger, R.G. Cooks, Desorption electrospray ionization mass spectrometry: Imaging drugs and metabolites in tissues, Proceedings of the National Academy of Sciences, 105 (2008) 18120-18125.

[29] A. Srimany, D.R. Ifa, H.R. Naik, V. Bhat, R.G. Cooks, T. Pradeep, Direct analysis of camptothecin from Nothapodytes nimmoniana by desorption electrospray ionization mass spectrometry (DESI-MS), Analyst, 136 (2011) 3066-3068.

[30] J.D. Watrous, P.C. Dorrestein, Imaging mass spectrometry in microbiology, Nat Rev Micro, 9 (2011) 683-694.

[31] J. Watrous, N. Hendricks, M. Meehan, P.C. Dorrestein, Capturing Bacterial Metabolic Exchange Using Thin Film Desorption Electrospray Ionization-Imaging Mass Spectrometry, Analytical Chemistry, 82 (2010) 1598-1600.

[32] D.R. Ifa, N.E. Manicke, A.L. Dill, R.G. Cooks, Latent fingerprint chemical imaging by mass spectrometry, Science, 321 (2008) 805-805.

[33] J.Y. Yew, R.B. Cody, E.A. Kravitz, Cuticular hydrocarbon analysis of an awake behaving fly using direct analysis in real-time time-of-flight mass spectrometry, Proceedings of the National Academy of Sciences, 105 (2008) 7135-7140.

[34] J. Liu, H. Wang, R.G. Cooks, Z. Ouyang, Leaf Spray: Direct Chemical Analysis of Plant Material and Living Plants by Mass Spectrometry, Anal Chem, 83 (2011) 7608-7613.

[35] J. Liu, R.G. Cooks, Z. Ouyang, Biological Tissue Diagnostics Using Needle Biopsy and Spray 
Ionization Mass Spectrometry, Anal Chem, 83 (2011) 9221-9225.

[36] K. Yoshimura, L.C. Chen, Z. Yu, K. Hiraoka, S. Takeda, Real-time analysis of living animals by electrospray ionization mass spectrometry, Analytical Biochemistry, 417 (2011) 195-201.

[37] H. Chen, A. Wortmann, W. Zhang, R. Zenobi, Rapid In Vivo Fingerprinting of Nonvolatile Compounds in Breath by Extractive Electrospray Ionization Quadrupole Time-of-Flight Mass Spectrometry, Angewandte Chemie International Edition, 46 (2007) 580-583.

[38] I. Cotte-Rodríguez, C.C. Mulligan, R.G. Cooks, Non-Proximate Detection of Small and Large Molecules by Desorption Electrospray Ionization and Desorption Atmospheric Pressure Chemical Ionization Mass Spectrometry: Instrumentation and Applications in Forensics, Chemistry, and Biology, Analytical Chemistry, 79 (2007) 7069-7077.

[39] J. Balog, T. Szaniszlo, K.-C. Schaefer, J. Denes, A. Lopata, L. Godorhazy, D. Szalay, L. Balogh, L. Sasi-Szabo, M. Toth, Z. Takats, Identification of Biological Tissues by Rapid Evaporative Ionization Mass Spectrometry, Analytical Chemistry, 82 (2010) 7343-7350.

[40] J. Balog, L. Sasi-Szabó, J. Kinross, M.R. Lewis, L.J. Muirhead, K. Veselkov, R. Mirnezami, B. Dezső, L. Damjanovich, A. Darzi, J.K. Nicholson, Z. Takáts, Intraoperative Tissue Identification Using Rapid Evaporative Ionization Mass Spectrometry, Science Translational Medicine, 5 (2013) 194ra193-194ra193.

[41] D.R. Ifa, J.M. Wiseman, Q. Song, R.G. Cooks, Development of capabilities for imaging mass spectrometry under ambient conditions with desorption electrospray ionization (DESI), International Journal of Mass Spectrometry, 259 (2007) 8-15.

[42] L.S. Eberlin, I. Norton, D. Orringer, I.F. Dunn, X. Liu, J.L. Ide, A.K. Jarmusch, K.L. Ligon, F.A. Jolesz, A.J. Golby, S. Santagata, N.Y.R. Agar, R.G. Cooks, Ambient mass spectrometry for the intraoperative molecular diagnosis of human brain tumors, Proc Natl Acad Sci U S A, 110 (2013) 1611-1616.

[43] R.G. Cooks, N.E. Manicke, A.L. Dill, D.R. Ifa, L.S. Eberlin, A.B. Costa, H. Wang, G. Huang, Z. Ouyang, New ionization methods and miniature mass spectrometers for biomedicine: DESI imaging for cancer diagnostics and paper spray ionization for therapeutic drug monitoring, Faraday Discussions, 149 (2011) 247-267.

[44] M. Siebenhaar, K. Küllmer, N.M. Barros Fernandes, V. Hüllen, C. Hopf, Personalized monitoring of therapeutic salicylic acid in dried blood spots using a three-layer setup and desorption electrospray ionization mass spectrometry, Analytical and Bioanalytical Chemistry, 407 (2015) 7229-7238.

[45] L. Nyadong, S. Late, M.D. Green, A. Banga, F.M. Fernández, Direct Quantitation of Active Ingredients in Solid Artesunate Antimalarials by Noncovalent Complex Forming Reactive Desorption Electrospray lonization Mass Spectrometry, Journal of the American Society for Mass Spectrometry, 19 (2008) 380-388.

[46] H. Wang, J. Liu, R.G. Cooks, Z. Ouyang, Paper Spray for Direct Analysis of Complex Mixtures Using Mass Spectrometry, Angewandte Chemie International Edition, 49 (2010) 877-880.

[47] V. Kertesz, G.J. Van Berkel, Fully automated liquid extraction-based surface sampling and ionization using a chip-based robotic nanoelectrospray platform, J Mass Spectrom, 45 (2010) 252-260.

[48] Y. Ren, J. Liu, L. Li, M.N. McLuckey, Z. Ouyang, Direct mass spectrometry analysis of untreated samples of ultralow amounts using extraction nano-electrospray, Analytical Methods, 5 (2013) 6686-6692.

[49] L. Gao, Q. Song, G.E. Patterson, R.G. Cooks, Z. Ouyang, Handheld Rectilinear Ion Trap Mass 
Spectrometer, Analytical Chemistry, 78 (2006) 5994-6002.

[50] L. Gao, A. Sugiarto, J.D. Harper, R.G. Cooks, Z. Ouyang, Design and Characterization of a Multisource Hand-Held Tandem Mass Spectrometer, Analytical Chemistry, 80 (2008) 7198-7205.

[51] L. Li, T.-C. Chen, Y. Ren, P.I. Hendricks, R.G. Cooks, Z. Ouyang, Mini 12, Miniature Mass Spectrometer for Clinical and Other Applications-Introduction and Characterization, Anal Chem, 86 (2014) 2909-2916.

[52] K. Hou, W. Xu, J. Xu, R.G. Cooks, Z. Ouyang, Sampling Wand for an Ion Trap Mass Spectrometer, Anal Chem, 83 (2011) 1857-1861.

[53] W. Xu, N. Charipar, M.A. Kirleis, Y. Xia, Z. Ouyang, Study of Discontinuous Atmospheric Pressure Interfaces for Mass Spectrometry Instrumentation Development, Analytical Chemistry, 82 (2010) 6584-6592.

[54] L. Gao, R.G. Cooks, Z. Ouyang, Breaking the Pumping Speed Barrier in Mass Spectrometry: Discontinuous Atmospheric Pressure Interface, Analytical Chemistry, 80 (2008) 4026-4032.

[55] C.-H. Chen, Z. Lin, S. Garimella, L. Zheng, R. Shi, R.G. Cooks, Z. Ouyang, Development of a Mass Spectrometry Sampling Probe for Chemical Analysis in Surgical and Endoscopic Procedures, Anal Chem, 85 (2013) 11843-11850.

[56] C.-H. Chen, Z. Lin, R. Tian, R. Shi, R.G. Cooks, Z. Ouyang, Real-Time Sample Analysis Using a Sampling Probe and Miniature Mass Spectrometer, Anal Chem, 87 (2015) 8867-8873.

[57] X. Ma, M. Zhao, Z. Lin, S. Zhang, C. Yang, X. Zhang, Versatile Platform Employing Desorption Electrospray Ionization Mass Spectrometry for High-Throughput Analysis, Analytical Chemistry, 80 (2008) 6131-6136.

[58] T.A. Brown, H. Chen, R.N. Zare, Identification of Fleeting Electrochemical Reaction Intermediates Using Desorption Electrospray Ionization Mass Spectrometry, Journal of the American Chemical Society, 137 (2015) 7274-7277.

[59] R.H. Perry, T.J. Cahill, J.L. Roizen, J. Du Bois, R.N. Zare, Capturing fleeting intermediates in a catalytic C-H amination reaction cycle, Proceedings of the National Academy of Sciences, 109 (2012) 18295-18299.

[60] R.H. Perry, K.R. Brownell, K. Chingin, T.J. Cahill, R.M. Waymouth, R.N. Zare, Transient Ru-methyl formate intermediates generated with bifunctional transfer hydrogenation catalysts, Proceedings of the National Academy of Sciences, 109 (2012) 2246-2250.

[61] P.I. Hendricks, J.K. Dalgleish, J.T. Shelley, M.A. Kirleis, M.T. McNicholas, L. Li, T.-C. Chen, C.-H. Chen, J.S. Duncan, F. Boudreau, R.J. Noll, J.P. Denton, T.A. Roach, Z. Ouyang, R.G. Cooks, Autonomous in Situ Analysis and Real-Time Chemical Detection Using a Backpack Miniature Mass Spectrometer: Concept, Instrumentation Development, and Performance, Anal Chem, 86 (2014) 2900-2908.

[62] H. Wang, N.E. Manicke, Q. Yang, L. Zheng, R. Shi, R.G. Cooks, Z. Ouyang, Direct Analysis of Biological Tissue by Paper Spray Mass Spectrometry, Analytical Chemistry, 83 (2011) 1197-1201.

[63] Q. Yang, N.E. Manicke, H. Wang, C. Petucci, R.G. Cooks, Z. Ouyang, Direct and quantitative analysis of underivatized acylcarnitines in serum and whole blood using paper spray mass spectrometry, Analytical and Bioanalytical Chemistry, 404 (2012) 1389-1397.

[64] R.D. Espy, S.F. Teunissen, N.E. Manicke, Y. Ren, Z. Ouyang, A. van Asten, R.G. Cooks, Paper Spray and Extraction Spray Mass Spectrometry for the Direct and Simultaneous Quantification of Eight Drugs of Abuse in Whole Blood, Analytical Chemistry, 86 (2014) 7712-7718. 
[65] L. Shen, J. Zhang, Q. Yang, N.E. Manicke, Z. Ouyang, High throughput paper spray mass spectrometry analysis, Clinica Chimica Acta, 420 (2013) 28-33.

[66] Y. Ren, S. Chiang, W. Zhang, X. Wang, Z. Lin, Z. Ouyang, Paper-capillary spray for direct mass spectrometry analysis of biofluid samples, Analytical and Bioanalytical Chemistry, 408 (2015) 1385-1390.

[67] Y. Ren, M.N. McLuckey, J. Liu, Z. Ouyang, Direct Mass Spectrometry Analysis of Biofluid Samples Using Slug-Flow Microextraction Nano-Electrospray Ionization, Angewandte Chemie International Edition, 53 (2014) 14124-14127.

[68] Q. Ma, H. Bai, W. Li, C. Wang, X. Li, R.G. Cooks, Z. Ouyang, Direct identification of prohibited substances in cosmetics and foodstuffs using ambient ionization on a miniature mass spectrometry system, Analytica Chimica Acta, DOI http://dx.doi.org/10.1016/j.aca.2016.01.031.

[69] Z. Zhang, W. Xu, N.E. Manicke, R.G. Cooks, Z. Ouyang, Silica Coated Paper Substrate for Paper-Spray Analysis of Therapeutic Drugs in Dried Blood Spots, Anal Chem, 84 (2012) 931-938.

[70] Y. Su, H. Wang, J. Liu, P. Wei, R.G. Cooks, Z. Ouyang, Quantitative paper spray mass spectrometry analysis of drugs of abuse, Analyst, 138 (2013) 4443-4447.

[71] G. Huang, H. Chen, X. Zhang, R.G. Cooks, Z. Ouyang, Rapid Screening of Anabolic Steroids in Urine by Reactive Desorption Electrospray Ionization, Analytical Chemistry, 79 (2007) 8327-8332.

[72] C. Wu, D.R. Ifa, N.E. Manicke, R.G. Cooks, Rapid, Direct Analysis of Cholesterol by Charge Labeling in Reactive Desorption Electrospray Ionization, Analytical Chemistry, 81 (2009) 7618-7624.

[73] J. Liu, H. Wang, N.E. Manicke, J.-M. Lin, R.G. Cooks, Z. Ouyang, Development, Characterization, and Application of Paper Spray Ionization, Analytical Chemistry, 82 (2010) 2463-2471.

[74] X. Zhou, J. Pei, G. Huang, Reactive paper spray mass spectrometry for in situ identification of quinones, Rapid Commun Mass Spectrom, 29 (2015) 100-106.

[75] M. Girod, E. Moyano, D.I. Campbell, R.G. Cooks, Accelerated bimolecular reactions in microdroplets studied by desorption electrospray ionization mass spectrometry, Chemical Science, 2 (2011) 501-510.

[76] R.M. Bain, C.J. Pulliam, R.G. Cooks, Accelerated Hantzsch electrospray synthesis with temporal control of reaction intermediates, Chemical Science, 6 (2015) 397-401.

[77] J.K. Lee, S. Banerjee, H.G. Nam, R.N. Zare, Acceleration of reaction in charged microdroplets, Quarterly Reviews of Biophysics, 48 (2015) 437-444.

[78] N.E. Manicke, Q. Yang, H. Wang, S. Oradu, Z. Ouyang, R.G. Cooks, Assessment of paper spray ionization for quantitation of pharmaceuticals in blood spots, International Journal of Mass Spectrometry, 300 (2011) 123-129.

[79] J. Liu, R.G. Cooks, Z. Ouyang, Enabling Quantitative Analysis in Ambient lonization Mass Spectrometry: Internal Standard Coated Capillary Samplers, Anal Chem, 85 (2013) 5632-5636.

[80] L. Li, X. Zhou, J.W. Hager, Z. Ouyang, High efficiency tandem mass spectrometry analysis using dual linear ion traps, Analyst, 139 (2014) 4779-4784.

[81] J.S. Sampson, A.M. Hawkridge, D.C. Muddiman, Generation and Detection of Multiply-Charged Peptides and Proteins by Matrix-Assisted Laser Desorption Electrospray Ionization (MALDESI) Fourier Transform Ion Cyclotron Resonance Mass Spectrometry, Journal of the American Society for Mass Spectrometry, 17 (2006) 1712-1716.

[82] E.G. Bligh, W.J. Dyer, A rapid method of total lipid extraction and purification, Canadian Journal of Biochemistry and Physiology, 37 (1959) 911-917.

[83] Y. Li, Y. Li, T. Chen, A.S. Kuklina, P. Bernard, F.J. Esteva, H. Shen, M. Ferrari, Y. Hu, Circulating 
Proteolytic Products of Carboxypeptidase N for Early Detection of Breast Cancer, Clinical Chemistry, 60 (2014) 233-242. 